\title{
Chest pain and aphasia in a young male
}

\author{
Al Jalbout $\mathrm{N}^{*}$ and Omron $\mathrm{R}^{2}$ \\ ${ }^{1}$ M.D., Chief Resident, Department of Emergency Medicine, Johns Hopkins University School of Medicine, Baltimore, Maryland, USA \\ ${ }^{2}$ M.D., MPH, Assistant Professor, Department of Emergency Medicine, Johns Hopkins University School of Medicine, Baltimore, Maryland, USA
}

\section{Case presentation}

A 30-year-old male with history of diabetes and intravenous drug use (IVDU) presents to the emergency department (ED) for acute onset right-sided weakness. Patient presented to the nursing staff in jail complaining of severe left sided chest pain radiating to the back. Suddenly, he became diaphoretic and developed dense aphasia. Upon arrival to the $\mathrm{ED}$, his temperature was 36 degrees Celsius, blood pressure was $116 / 41 \mathrm{mmHG}$, heart rate was 86 , and respiratory rate was 18 . On exam, he had complete right-sided motor weakness, facial droop, and hemineglect.

CT of the head and CT angiography of the chest, abdomen, and pelvis were done emergently. CT head showed an acute infarct involving right occipital and left temporal lobes. CT angiography showed no evidence of acute vascular dissection or occlusion. An immediate bedside echocardiography was done (Images) revealing a hyper-echoic structure at the level of the aortic valve.

\section{Images}

Parasternal long (Figure 1 and 2) and parasternal short axis views (Figure 3) were notable for large vegetation on the aortic valve, an aortic root abscess, concerning for aortic valve endocarditis.

\section{Discussion}

The patient was started on intravenous antibiotics and admitted to the neurology intensive care unit. He developed cerebral edema within 24 hours, then herniated and arrested.

Among IVDUs, aortic valve endocarditis is a rare entity with high morbidity and mortality $[1,2]$. It indicates severe disease with mortality rate up to thirty percent [3]. Patients are at risk of developing systemic embolization to the brain, kidneys, and spleen. Patients with embolic

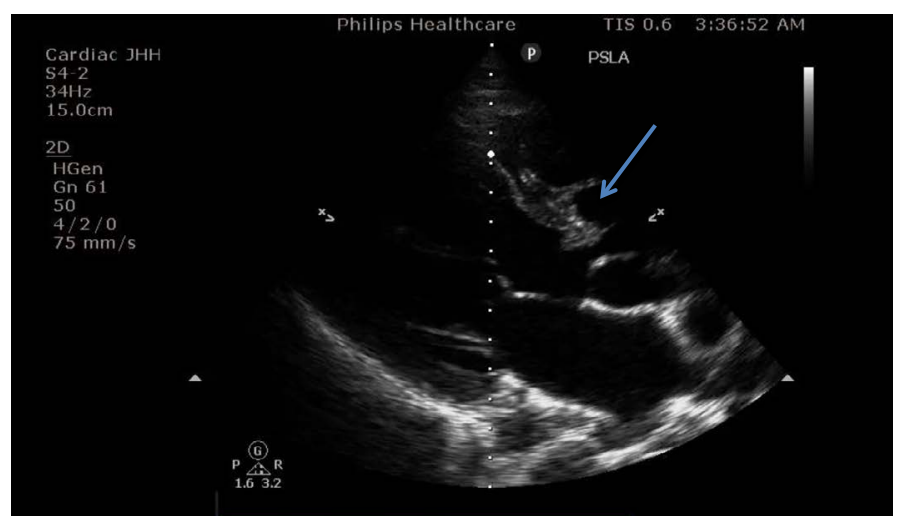

Figure 1. Parasternal long axis view showing the vegetation on the aortic valve

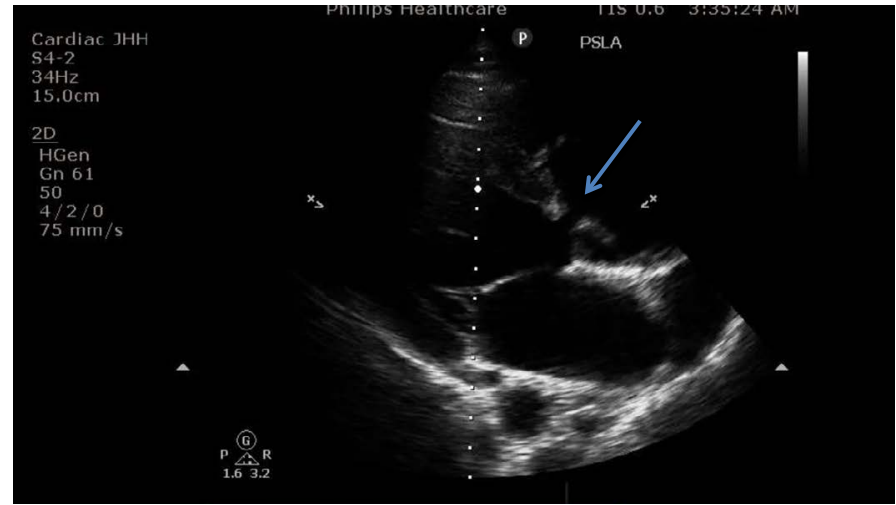

Figure 2. Parasternal long axis view showing the vegetation on the aortic valve

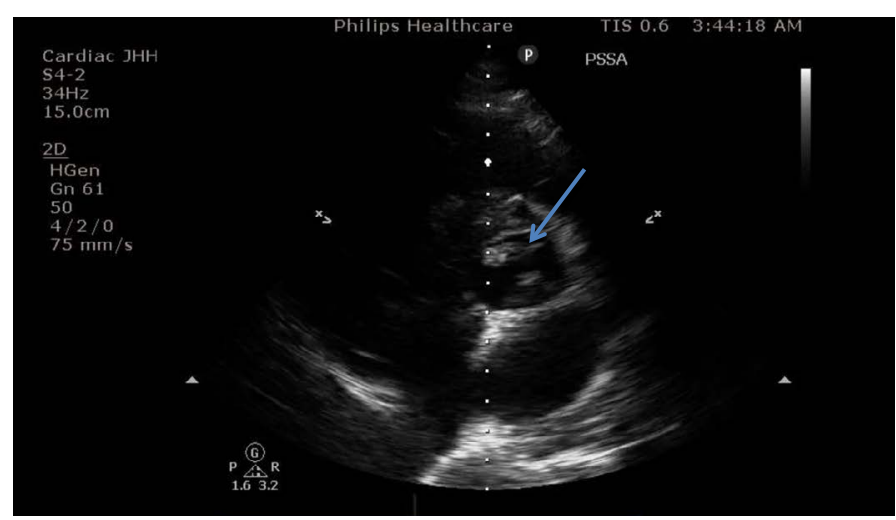

Figure 3. Parasternal short axis view showing the aortic valve vegetation

cerebrovascular accidents (CVA) develop cytotoxic cerebral edema requiring close neurological monitoring. While the management of most embolic CVAs is intravenous tissue plasminogen activator, patients with infective embolic CVAs are candidates for intravenous antibiotics or washout hemicraniectomy.

Among IVDUs, physicians must have a low index of suspicion for embolic etiologies of CVAs, in order to guide the appropriate therapy. Point of care ultrasound provides an important bedside diagnostic modality in this subpopulation to evaluate for sources of emboli.

${ }^{*}$ Correspondence to: Al Jalbout N, M.D, Chief Resident, Department of Emergency Medicine, Johns Hopkins University School of Medicine, 1830 E monument street, Suite 6-100, Baltimore, 21287, Maryland, USA, E-mail: naljalb1@jhmi.edu

Received: April 02, 2018; Accepted: April 09, 2018; Published: April 12, 2018 


\section{Conflicts of interest}

None

\section{Financial support}

None

\section{References}

1. Seghatol F, Grinberg I (2002) Left-sided endocarditis in intravenous drug users: a case report and review of the literature. Echocardiography 19: 509-511.

2. Ji Y, Kujtan L, Kershner D (2012) Acute endocarditis in intravenous drug users: a case report and literature review. J Community Hosp Intern Med Perspect 2. [Crossref]

3. Baddour LM, Wilson WR, Bayer AS, Fowler VG, Tleyjeh IM, et al. (2015) Infective Endocarditis in Adults: Diagnosis, Antimicrobial Therapy, and Management of Complications: A Scientific Statement for Healthcare Professionals from the American Heart Association. Circulation 132: 1435-1486.

Copyright: (C2018 Al Jalbout N. This is an open-access article distributed under the terms of the Creative Commons Attribution License, which permits unrestricted use, distribution, and reproduction in any medium, provided the original author and source are credited. 